\title{
Clinical decision support systems in critical care during covid-19
}

Juan Martin Lazaro ${ }^{1 *}$, James Kelly ${ }^{1}$ and Pablo Alamo ${ }^{2}$

${ }^{1}$ Intensive Care Unit, Newham University Hospital, London.

2 CETYS University, Mexico.

*Corresponding Author: Juan Martin Lazaro, Intensive Care Unit, Newham University Hospital, London.

Received date: February 11, 2021; Accepted date: February 15, 2021; Published date: February 22,2021

Citation: Juan M. Lazaro, Kelly J. and Alamo P. (2021) Clinical decision support systems in critical care during covid-19 Clinical Medical Reviews and Reports 3(2); DOI: 10.31579/2690-8794/064

Copyright: (C) 2021, Juan Martin Lazaro, This is an open access article distributed under the Creative Commons Attribution License, which permits unrestricted use, distribution, and reproduction in any medium, provided the original work is properly cited.

We congratulate Alexander Supady and colleagues for their recent informative work on rationing decisions for COVID-19 patients when resources are scarce [1]. We appreciate the proposal of involving triage committees in the application of rationing. However, we suggest that the clinical needs are somewhat broader than those discussed in this work.

With the first wave of COVID-19 we learnt to optimise care by utilitarian and egalitarian principles of prioritisation, which provided a reasonable method of rationing resources. In the second wave of COVID-19 we have taken a different approach, because more equipment and resources were initially available. Generally, we tried to save more lives, and put aside, at least for a while, utilitarian rationing. However, it was realised that incrementing equipment and resources soon led to a lack of specialised personnel, and would potentially overwhelm the healthcare system in the United Kingdom and globally.

The input of triage committees is timely because it can help address several other significant problems intensivists face beyond the question of who should be admitted to an intensive care unit. These problems include: when is the right moment to withdraw care? Which patients should be palliated? which patients should be escalated to dialysis or inotropes?

Clinical Decision Support (CDS) systems must be developed to increase equity and reduce the burden these decisions place on clinicians particularly now that it is becoming more widely recognised that taking such decisions has the potential to inflict occupational moral injury on clinicians [2]. The 4C Deterioration Model and the 4C Mortality Score arose during the first wave as potential solutions. More complex tools have emerged, such as the COVID-19 Severity Score, and risk factors in a statistical learning algorithm to predict mortality [3]. However, such tools are still only targeted at the questions of admission to ICU and mortality.
Of course, clinicians need to use their judgement to make decisions that are at all times realistic and impartial [4], but they would benefit greatly from tools to answer the additional pressings questions above. These tools have the potential to help clinicians make clearer decisions based on more rational support than family or system pressures, and to save lives by prioritizing critical care in patients at high risk for adverse outcomes [5]. Traditional tools such as SOFA scoring have become obsolete, showing no accuracy in end of life care decisions in the context of a viral pandemic. There is an urgent need for a COVID-19 disease severity assessment that can assist in critical care in resource allocation for patients at risk for severe disease.

\section{Reference}

1. Supady A, Curtis JR, Abrams D, Lorusso R, Bein T, et al. (2021) Allocating scarce intensive care resources during the COVID-19 pandemic: practical challenges to theoretical frameworks. Lancet Respir Med. S2213-2600(20)30580-4.

2. Greenberg N, Docherty M, Gnanapragasam S, et al. (2020) Managing mental health challenges faced by healthcare workers during covid-19 pandemic. BMJ. 368:m1211.

3. McRae MP, Simmons GW, Christodoulides NJ, Lu Z, Kang SK, et al. (2020) Clinical decision support tool and rapid point-of-care platform for determining disease severity in patients with COVID19. Lab Chip. 20(12):2075-2085.

4. Bastons M, Armengou J. (2017) Realism and Impartiality: Making Sustainability Effective in Decision-Making. Sci Eng Ethics. 23(4):969-987.

5. McRae MP, Dapkins IP, Sharif I, Anderman J, Fenyo D, et al. (2020) Managing COVID-19 With a Clinical Decision Support Tool in a Community Health Network: Algorithm Development and Validation. J Med Internet Res. 22(8):e22033. 